\title{
INCENTIVES FOR SOCIAL MEDIA USERS' ENGAGEMENT TO DIFFERENT BRAND-RELATED CONTENT TYPES
}

\author{
Nikolina Palamidovska-Sterjadovska \\ Faculty of Economics - Skopje, Ss. Cyril and Methodius University \\ nikolina@eccf.ukim.edu.mk \\ Anita Ciunova-Shuleska \\ Faculty of Economics - Skopje, Ss. Cyril and Methodius University \\ anita.ciunova@eccf.ukim.edu.mk
}

\begin{abstract}
The purpose of this study is to analyze social media users' incentives for engagement with brand-related content on social media. Based on the uses and gratification theory, two types of incentives are analyzed as motivators of users' brand engagement, i.e. communal and selfinterest incentives. Users' brand engagement is conceptualized and measured as intentions to contribute to brand-related content on social media in terms of intentions for commenting, sharing, and liking. Further, it is assumed that the effects of the two types of incentives (communal and self-interest) vary depending on the brand-related content type (commercial messages, personal opinions and lifestyle affairs). An online survey was conducted for obtaining quantitative data which were analyzed by applying structural equation modeling. The total number of effective responses is 415 . The results indicate that only communal incentives motivate users to contribute to brand-related commercial messages, personal opinions and lifestyle affairs. The obtained results could be utilized by brand marketers in effectively designing brand-related content on social media.
\end{abstract}

Keywords: brand, communal incentives, self-interest incentives, engagement, contribution, content type

\section{JEL classification: $M 31$}

\section{INTRODUCTION}

With the rise and proliferation of social media, customers are able to communicate more proactively, they are no longer "passive" consumers of marketing content, instead, they are involved in co-creation and multiplication of brand messages on social media (Jahn and Kunz, 2012). Businesses have realized they can use social media to create, strengthen, and enhance the relationships with customers, to create brands and increase brand's customer engagement (Tsimonis, and Dimitriadis, 2014).

Customer brand engagement on social media is a relatively new marketing phenomenon and its conceptualization and measurement have not been explored in depth so far (Schivinski et al., 2016; Barger et al., 2016). It is defined as 'customers' behavioral manifestation toward a brand or firm, beyond purchase, resulting from motivational drivers" (Van Doorn et al., 2010, p. 254).

The brand-related users' activities differ in terms of level of engagement (de Vries et al., 2017), starting from consuming (reading posts, watching photos/videos) through contributing (commenting, sharing, liking) to creating brand-related content (creating postings, photos, and videos) (Muntinga et al., 2011). Consuming or lurking is the most frequent type of engagement 
where consumers have only passive role, while contributing and creating refer to moderate and high level of engaging brand-related activities (de Vries et al., 2017).

Based on the uses and gratifications theory (Katz, 1959), users' motivations are analyzed as incentives to interact with brands on social media. The uses and gratifications approach to communication research examines how and why people use media (Katz, 1959) and explains the psychological incentives that motivate people to choose a specific media (Cheung et al., 2011). Therefore, this theory can be used as a foundation in explaining why people use social media (Raacke and Bonds-Raacke, 2008; Shao, 2009) and consequently why engage in brandrelated content on social media. The widely recognized McQuail's (1983) four-category classification of motivations for general media use has been used for explaining Internet and social media use (Malthouse and Calder, 2010; Muntinga et al., 2011; Quan-Haase and Young, 2010). The proposed categories of motivations by McQuail (1983) are entertainment, integration and social interaction, personal identity and information. In addition to these, Muntinga et al. (2011) proposed remuneration and empowerment as information motivations specific to social media context, while Azar et al. (2016) proposed social influence, search for information, entertainment, trust and reward as motivations to interact on Facebook.

De Vries et al. (2017) suggested that brand-related activities on social media usually are affected by motivations ranging from fully intrinsic to fully extrinsic, i.e. entertainment and remuneration at the extremes and in between are self-expression, socializing, and obtaining information/knowledge. They indicated that self-expression and socializing as incentives have primary role in users' participation in moderately and highly engaging activities.

By applying the concepts of uses and gratifications theory and based on the studies of Fu et al. (2017) and de Vries et al. (2017), two types of incentives are analyzed in this research, i.e. communal and self-interest incentives and their influence on the social media users' intentions for brand engagement. Having in mind the interactive and co-creative nature of social media, this paper focuses on contributing activities as a moderate level of engagement, based on the prior work of Muntinga et al. (2011) and Schivinski et al. (2016). Further, considering that participation of users on social media is influenced by content strategy (Thongmak, 2015), different content types are analyzed in this study. Namely, three content types are applied (commercial messages, personal opinions and lifestyle affairs) based on the work of Fu et al. (2017), at the same time extending their work by analyzing not only sharing intentions but also intentions to like and comment brand-related content on social media.

Consequently, the objective of this study is to explore the influence of two types of incentives as antecedents of intentions to contribute to brand-related content depending on the content type. This work offers multiple contributions in the field of brand-related engagement of social media users. First, it examines moderate level of users' brand-related engagement on social media, i.e. contributing rather than focusing on consuming brand-related content on social media, thus extending the limited research findings related to contributing topics in social media marketing literature (de Vries et al., 2017). Secondly, this study analyses the simultaneous influence of two types of incentives (communal and self-interest) as drivers of intentions to contribute brand-related content on social media. The previous studies analyzed motivations of more general and passive activities on social media and only a few studies have analyzed the influence of incentives on user brand engagement on social media (de Vries et al., 2017). Thirdly, this study posits that the type of brand-related content (commercial messages, lifestyle affairs or personal opinions) determines the relationship between the incentives and intentions to brand-related contributing activities of social media users.

The remainder of the paper is organized as following: first, literature review and development of hypotheses is presented; followed by methodology and data analysis and results. At the end, conclusions and implications are discussed. 


\section{LITERATURE REVIEW}

Generally, content type has been suggested as an important aspect of the strategy in the previous marketing literature (Chauhan and Pillai, 2013). Vargo (2016) empirically proved that content type of brand-related posts has a significant effect on number of retweets and likes, while de Vries et al. (2012) suggested that the content of brand post is one of the factors driving brand post popularity. Moreover, the research studies of Cvijikj and Michahelles (2013), Karpinska-Krakowiak and Modlinski (2020), Moran et al. (2019), Luarn et al. (2015) indicated that content type of brand posts is a significant factor for all measures of engagement (liking, commenting and sharing) on social media, applying diverse classifications of content type. Similarly, Fu et al. (2017) stated that share intentions of social media users are subject to content type. As posting brand-extended content (commercial messages) by the company leads to increase of the number of consumers and posting "unprofessional" content (noncommercial messages) leads to development of relational bonding (Kaplan and Haenlein, 2010), it can be assumed that users' contribution to different brand content (commercial messages and noncommercial such as personal opinions and lifestyle affairs) will increase as a result of social and personal incentives.

Communal (socializing) incentives: People use different social media for different reasons, among them for sharing problems, for social knowledge and sociability (Phua et al., 2017). Park et al. (2009) claimed that people use social media to gratify their socializing needs. Social media are also used for self-promoting (broadcasting) or maintaining relationships (communicating) (Underwood et al. (2011)), for social interaction, and for exchanging information to feel more connected to others (Chen, 2011; Sheldon et al., 2011) and to fulfill the need for community commitment (Walsh et al., 2004). Building and maintaining social connections is one of the motives for using social media like Facebook (Joinson, 2008; QuanHaase and Young, 2010). In participation in moderately engaging activities (i.e. collaborating with others to contribute to content) people are highly motivated by the desires for socializing (de Vries et al., 2017).

Tsai and Men (2013) claimed that parasocial interaction and community identification play a significant role in encouraging customer engagement on social media. Socializing with others lead people to engage in brand-related contributing activities on social media i.e. to collaborate with other users in the brand-related content generation process (contributing) (de Vries et al., 2017) Chi (2011) found that the need for bonding social capital created by online social interactions and networking has significant influence on participation intention in Facebook advertising activities. According to Fu et al. (2017) communal incentive drives social media users' content sharing intention and the effects depend on the content type.

Based on the above mentioned the following hypotheses are defined:

H1. Communal incentives positively influence intentions to contribute to brand-related commercial messages on social media

$\mathrm{H} 2$ : Communal incentives positively influence intentions to contribute to brand-related personal opinions on social media

H3: Communal incentives positively influence intentions to contribute to brand-related lifestyle affairs on social media

Self-interest (personal) incentives:_Self-motives are initial drivers of word of mouth activities through which one strives to boost her/his self-image and to protect the ego (Alexandrov et al., 2013). These incentives refer to users' intrinsic utility (Toubia \& Stephen, 2013) which leads to "doing an activity for its inherent satisfactions rather than for some separable consequence" (Ryan and Deci 2000, p. 56). On social media, users not only socialize with others (Ellison et al., 2007), but also manage their identities and their self-presentation (Zhao et al., 2008; Ong et al., 2011) by liking, commenting and sharing activities (Lee et al., 2014). Users engage in 
such activities on social media in order to express and present themselves (de Vries et al., 2017), communicating one's personality and personal identity (Aaker, 1999). In the study of Muntinga et al. (2011), the personal identity aspects are covered by three sub-motivations (selfpresentation, self-expression and self-assurance) related to contributing to brand-related content.

Based on the assumption that humans are self-interested, Shao (2009) analyzed self-expression and self-actualization as drivers of activities on user-generated media. Self-expression is related to brand-related activities on social media (Ryan and Deci, 2000; de Vries et al., 2017) where users are likely to participate in order to seek and maintain their personal status (Park et al., 2009). The motive for self-actualization also induce certain engagement as support of ones' own identity and personality (Trepte, 2005). Additionally, self-promotion is one of the reasons for consumers' contribution to content on social media (Berthon et al., 2008). Self-interest incentives lead to higher intention to engage in brand-related activities on social media (Buffardi and Campbell, 2008; Tennie et al., 2010), such as sharing a content about product information or some promotional opportunities (Fu et al., 2017).

Based on the previously explained, the following hypotheses are proposed:

H4: Self-interest incentives positively influence intentions to contribute to brand-related commercial messages on social media

H5: Self-interest incentives positively influence intentions to contribute to brand-related personal opinions on social media

H6: Self-interest incentives positively influence intentions to contribute to brand-related lifestyle affairs on social media

\section{METHODOLOGY}

\section{Measures}

All the variables applied in the research model were operationalized and measured based on the relevant literature in this area. Namely, social incentives (connection, altruism, and group joy) and self-interest incentives (achievement, self-expression, and loneliness) were adapted from $\mathrm{Fu}$ et al. (2017), while customers' intention to contribute to brand-related content were developed based on the study of Muntinga et al. (2011), Schivinski et al. (2016) and Fu et al. (2017). In this study, contributing intentions are measured in terms of intentions for liking, commenting and sharing on social media and refer to three different brand-related content types, i.e. commercial messages (promotion announcements and new product information), personal opinions (pleasant shopping experience and critical arguments) and lifestyle affairs (practical wisdom and inspiring articles). In these two sections, a Likert scale was applied where incentives were measured on a scale from 1 (strongly disagree) to 7 (strongly agree), while contributing intentions by content types were measured on a scale from 1 (strongly disagree) to 5 (strongly agree). Additionally, the questionnaire comprised sections of demographic data (age, gender, level of studies, and household income level) and psychographic data (social media usually used and usage intensity).

All the measurement items/questions were initially adapted from English and further translated to Macedonian, followed by a backward translation. The wording of the items was further improved by the feedback generated from questionnaire pre-testing on a sample of nine respondents. In Table 1 are presented the measurement items and their factor loadings.

\section{Sampling}

Data collection based on the final research instrument was conducted through online surveys, applying the snowballing sampling technique for reaching the target respondents, i.e. university students. A total number of 422 responses were generated and after the data cleaning, 415 effective responses were retained and further analyzed. 
The majority of the respondents are women (66.5\%) with an average age of 22.9 years. Most of them are at first cycle of studies (81.4\%) and their household monthly incomes mostly range from 25.001 to 40.000 den. (33.0\%). Regarding social media, most of them usually use Instagram $(74.2 \%)$, followed by Facebook $(17.9 \%)$, mostly spending daily up to $30 \mathrm{~min}$. $(27.5 \%)$, followed by "up to one hour" (23.4\%) and "up to two hours" $(20.0 \%)$ and more $(29.1 \%)$.

\section{DATA ANALYSIS AND RESULTS}

The developed research model (see Figure 1) was analyzed first by performing confirmation factor analysis (CFA) for assessing the measurement model and further by conducting structural equation modeling (SEM) for evaluating the structural model. All the analysis were conducted by applying AMOS 20.0. Below are presented the results.

\section{Figure 1. Conceptual model}

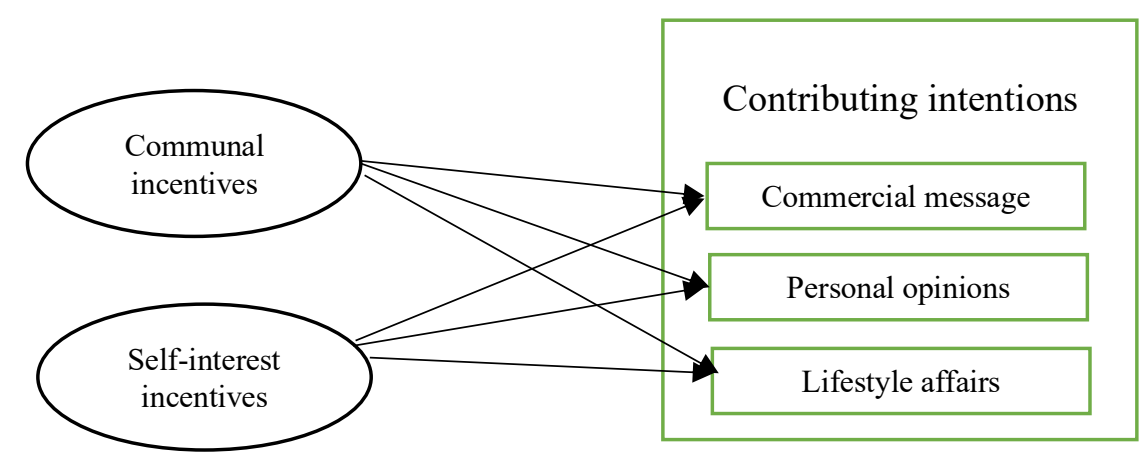

\section{Measurement model analysis}

The results obtained by performing CFA suggested that the measurement model was adequate, i.e. all the fit indices are above the required thresholds (Hair et al., 2010) $(\mathrm{CMIN} / \mathrm{df}=2.059$; $\mathrm{GFI}=0.9 ; \mathrm{AGFI}=0.876 ; \mathrm{CFI}=0.958 ; \mathrm{NFI}=0.922 ; \mathrm{RMSEA}=0.051)$. Further, the construct validity was evaluated in terms of convergent and discriminant validity.

Composite reliability (CR) and average variance extracted (AVE) of the latent variables are presented in Table 2, indicating adequate level of convergent validity. Namely, all the CR and AVE values are above the recommended minimum ( 0.7 and 0.5 , respectively) (Hair et al., 2010). Additionally, the factor loadings of the measurement items are above 0.7 and all of them are statistically significant (see Table 1).

\section{Table 1. Measurement model assessment}

\section{Construct name and measurement items}

Communal incentives (CI) $(\boldsymbol{\alpha}=\mathbf{0 . 8 2 6})$

I interact with brands on social network sites in order to share helpful information

I interact with brands on social network sites to have group fun with friends

I interact with brands on social network sites in order to keep in touch with friends

Self-interest incentives (SSI) $(\boldsymbol{\alpha}=\mathbf{0 . 8 2 8})$

I interact with brands on social network sites to gain sense of achievement

I interact with brands on social network sites to express self

I interact with brands on social network sites to seek for companionship

Intentions to contribute to commercial messages $(\mathrm{CM})(\alpha=0.914)$ 
I intent to put comments on posts/photos/videos related to new product information

I intent to share posts/photos/videos related to new product information

I intent to put comments on posts/photos/videos related to promotion activities

I intent to share posts/photos/videos related to promotion activities

I intent to put comments on posts/photos/videos related to industrial news

I intent to share posts/photos/videos related to industrial news

0.710

I intent to put comments on posts/photos/videos related to CSR events

0.744

Intentions to contribute to personal opinions (PO) $(\alpha=0.930)$

I intent to put comments on posts/photos/videos related to other people's experiences

about service quality store

I intent to share posts/photos/videos related to other people's experiences about the service quality store

I intent to like posts/photos/videos related to other people's experiences about the service quality store

I intent to put comments on posts/photos/videos related to other people's experiences about product quality

I intent to share posts/photos/videos related to other people's experiences of buying low quality product

I intent to put comments on posts/photos/videos related to pleasant shopping

experiences

I intent to share posts/photos/videos related to pleasant shopping experiences

I intent to put comments on posts/photos/videos related to critical arguments (news or articles with critical opinions)

I intent to share posts/photos/videos related to critical arguments (news or articles with critical opinions)

Intentions to contribute to lifestyle affairs (LA) $(\alpha=0.891)$

I intent to put comments on inspiring articles

The discriminant validity was assessed by comparing the square roots of AVEs (presented in the diagonal cells) to the correlation coefficients of each pair of latent variables, as well to the maximum shared variance values (MSV). All the AVE values are higher than the comparing values, indicating adequate discriminant validity of the latent variables (Fornell and Larcker, 1981).

Table 2. Convergent and discriminant validity

\begin{tabular}{|l|c|c|c|c|c|c|c|c|}
\hline Construct name & CR & AVE & MSV & PO & CI & SII & CM & LA \\
\hline $\begin{array}{l}\text { Personal Opinions } \\
\text { (PO) }\end{array}$ & 0.928 & 0.592 & 0.446 & 0.769 & & & & \\
\hline $\begin{array}{l}\text { Community } \\
\text { Incentives (CI) }\end{array}$ & 0.839 & 0.640 & 0.475 & 0.311 & 0.800 & & & \\
\hline $\begin{array}{l}\text { Self-interest } \\
\text { Incentives (SII) }\end{array}$ & 0.828 & 0.616 & 0.475 & 0.362 & 0.689 & 0.785 & & \\
\hline $\begin{array}{l}\text { Commercial } \\
\text { Messages (CM) }\end{array}$ & 0.912 & 0.598 & 0.523 & 0.591 & 0.384 & 0.520 & 0.773 & \\
\hline Lifestyle Affairs (LA) & 0.893 & 0.677 & 0.523 & 0.668 & 0.301 & 0.363 & 0.723 & 0.823 \\
\hline
\end{tabular}




\section{Structural model analysis}

The maximum likelihood method of structural equation modeling was applied for assessing the structural model which was developed based on the validated measurement model. The goodness of fit indices indicate that the structural model is also adequate $(\mathrm{CMIN} / \mathrm{df}=2.005$; $\mathrm{GFI}=0.905 ; \mathrm{AGFI}=0.88$; $\mathrm{CFI}=0.961$;FI $=0.925$; $\mathrm{RMSEA}=0.049$ ).

Regarding the hypotheses testing, the results indicate the first set $(\mathrm{H} 1, \mathrm{H} 2$, and $\mathrm{H} 3)$ which refers to the relationship of communal incentives and customers' intentions to contribute to different content types on social media (commercial messages, personal opinions, lifestyle affairs, respectively) is statistically significant. Regarding the regression coefficients values, the results indicate that the relationship between communal incentives and intentions to contribute to lifestyle affairs content $(0.824)$ is the strongest; followed by commercial messages $(0.778)$ and personal opinion content (0.699). The second set of hypotheses (H4, H5, and H6) which refers to the impact of self-interest incentives on customers' intentions to contribute to commercial messages, to personal opinions, and to lifestyle affairs has not proved to be statistically significant (see Table 3).

\section{Table 3. Structural model estimation}

\begin{tabular}{lcc}
\hline $\begin{array}{l}\text { Hypothesised } \\
\text { relationships }\end{array}$ & $\begin{array}{c}\text { Standardized } \\
\text { Estimate }\end{array}$ & $\begin{array}{c}\text { p- } \\
\text { values }\end{array}$ \\
\hline H1: CI -> CM & 0.778 & 0.003 \\
H2: CI -> PO & 0.699 & 0.008 \\
H3: CI -> LA & 0.824 & 0.016 \\
H4: SSI -> CM & 0.039 & 0.933 \\
H5: SSI -> PO & 0.036 & 0.933 \\
H6: SSI -> LA & 0.047 & 0.933 \\
\hline
\end{tabular}

Regarding the coefficients of determination $\left(\mathrm{R}^{2}\right), 76.8$ percent of the variations in the intentions to contribute to lifestyle affairs are explained by the independent variables in the model; while the model accounts for 67.9 percent and 55.1 percent of the variations in the contributing intentions to personal opinions and commercial messages, respectively.

\section{CONCLUSIONS AND IMPLICATIONS}

To better understand what elicits the intentions to contribute to brand-related content on social media, this study explores the complementary impact of self-interest incentives and communal incentives on intentions to contribute to three types of brand-related content (commercial messages, personal opinions and lifestyle affairs) on social media.

The findings of this study add significantly to the growing literature based on users and gratification theory about drivers of social media users' intentions to engage in different types of brand-related content. Given the limited research on contributing intentions (like, comment, share) to different types of brand-related content on social media, the present analysis contributes to a greater understanding of what stimulates social media users to contribute to brand-related activities. Additionally, this research study contributes to the growing body of research that focuses on the brand-related content type on social media (Karpinska-Krakowiak and Modlinski, 2018, Vargo, 2016, Moran et al., 2019) by analyzing the content from different perspectives, to be precise, by analyzing lifestyle, commercial messages and personal opinions, following the perspective used by Fu et al. (2017).

The results of this study enriches the previous literature by highlighting the significant influence of communal incentives on intentions to contribute to brand-related content on social 
media. The findings generally suggest social incentives to be positive predictors of intentions to contribute to three different types of brand-related content on social media. This is in line with the findings of Chi (2011), Tsai and Men (2013), de Vries et al. (2017), and Fu et al. (2017) that relationship-oriented factors have a significant role in encouraging consumer engagement on social media. Therefore, companies should provide relevant information, interesting enough and at the same time appropriate for sharing, having fun and keeping in touch with friends i.e. for satisfying need for social interaction, which in turn will result in users' contribution to brand-related content on social media. Unexpectedly, the analyses show that self-interest incentives do not drive people to contribute to brand-related content no matter of the type of content. This is opposite to the findings of Schau and Gilly (2003) that customers intentionally choose the brands they will discuss in online communications in order to create positive self-images. Our findings can be explained in a certain way by the findings about consumer offline brand engagement that self-expression positively and significantly influences cognitive processing and affection but not the activation as dimensions of customer brand engagement (Leckie et al.2016). Therefore, the companies should avoid providing content suitable for self-promotion of the users, and provide content appropriate for satisfying users' communal need. The research results show that self-interest is a disincentive for contributing to brand-related content on social media. This can be explained with the findings of de Vries et al. (2017) who showed that self-expression of social media users is more related to creating activities comparing to contributing activities on social media. Consequently, it can be concluded that social media users driven by self-interest will be more likely engaged in creating postings, photos, and videos about the brand (creating) instead in commenting, sharing, liking brand-related content on social media (contributing) thus explaining the rejection of hypotheses $\mathrm{H} 4, \mathrm{H} 5$, and $\mathrm{H} 6$.

The present study has highlighted the central role that a communal incentives play in social media users' contributing activities to brand-related content. These findings are in line with the previous studies which analyze this relationship (de Vries et al., 2017; Fu et al., 2017; Vargo, 2016).

Additionally, the results of this study fills the research gap, by including the observation of different types of brand-related content the social media users contribute to, as very important issue in social media users' brand-related behavior. Namely, the results indicate that the relationship is the strongest between the communal incentives and intentions to contribute to brand-posts related to lifestyle. This is in line with the previous conclusion that the companies should provide content for satisfying social need such as content related to the lifestyle (inspiring articles, popular music and movies and practical wisdom) as the suitable content for having fun and staying connected with friends. The relationship between communal incentives and intentions to contribute to brand posts related to personal opinions about the brand is the weakest comparing to other two relationships, but is still strong and significant.

All these are consistent with the findings of Vargo (2016), who empirically proved that brand messages that mentioned popular culture events and current holidays or seasons (which refer to lifestyle affairs) strongly and positively influenced engagement on Twitter giving support to our findings regarding H1. This is also in line with the findings of Fu et al. (2017) who empirically proved that communal incentive drives users' intentions to share lifestyle affairs. The support of H2 is in line with the findings of Walsh et al. (2004) that a sense of community commitment defined by social interactions influence the likelihood of passing along content on social media to others. Additionally, promotional aspects of brand messages related to sweepstakes, content or giveaway (in this study commercial messages) have positively predicted engagement on social media (Vargo, 2016). The findings of this research study regarding the positive but weakest relationship between communal incentive and intentions to 
contribute to personal opinions related to brand (H3), are in line with findings of Vargo (2016) that this kind of relationship is significant but relatively weak.

Accordingly, businesses should pay attention and get deeper insights into what motivate people to contribute to brand-related content on social media and create a content that inspires "likes, comments, shares" on social media in order to appeal to them through their preferred content types. Based on this research study, when designing the brand-related content on social media, businesses should appeal to the social media users who are driven by their social motives though brand posts related to lifestyle affairs, commercial messages and at last personal opinions. In other words, posting content about lifestyle (inspiring articles, popular music and movies and practical wisdom) and commercial content (new product information, industrial news and promotional activities) related to the company/brand on official social media pages of the companies will result users' communal incentives to lead to higher intentions for contributing to brand-related content on social media. At the same time, companies should be aware that social media users are willing to like, put comments and share content generated by the users themselves driven by their need to have relationships with others (social need). Consequently, companies should be focused on providing the best product/service that will overjoy the users resulting in users' positive personal opinions about the product/service that will be posted on social media and afterwards liked, shared and commented by other social media users, accordingly spreading positive word of mouth about the company/product.

This research study has several research limitations among which two research limitations are perhaps the most noteworthy. The first issue relates to the non-probability sampling used in this study. Therefore, the results of this study may not be easily generalizable. Secondly, this study relies on a sample from one country, which again limits the generalization of the results. Thirdly, in a lack of actual behaviour data, this study analyses users' intentions as a proxy for brand engagement on social media and therefore some gaps are expected. Nevertheless, the limitations of the study present opportunity for future research. In future, data mining techniques should be applied in order to analyze the actual social media users' engagement. Further, additional incentives for brand-related engagement activities could be simultaneously analyzed with the communal and self-interest incentives in order to better understand what prompts the social media users to contribute to brand-related content on social media. Furthermore, future studies should explore contributing together with creating brand-related activities with focus on different types of brand-related content. The moderating role of the social capital in the relationship between the incentives and intentions to contributing and creating different types of brand-related content on social media can be explored as well. In addition, the authors recognize that findings may differ across different social media given the differences in their characteristics. Thus, user's engagement to different brand-related content type on specific social media can be analyzed too.

\section{REFERENCES}

Aaker, J.L. (1999), “The malleable self: The role of self-expression in persuasion", Journal of Marketing Research, Vol. 36 No. 1, pp.45-57.

Alexandrov, A., Lilly, B. and Babakus, E. (2013), "The effects of social-and self-motives on the intentions to share positive and negative word of mouth", Journal of the Academy of Marketing Science, Vol. 41 No. 5, pp.531-546.

Azar, S.L., Machado, J.C., Vacas-de-Carvalho, L. and Mendes, A. (2016), "Motivations to interact with brands on Facebook-Towards a typology of consumer-brand interactions", Journal of Brand Management, Vol. 23 No. 2, pp.153-178. 
Barger, V., Peltier, J.W. and Schultz, D.E. (2016), "Social media and consumer engagement: a review and research agenda", Journal of Research in Interactive Marketing, Vol. 10 No. 4, pp. 268-287.

Berthon, P., Pitt, L. and Campbell, C. (2008), "Ad lib: When customers create the ad", California Management Review, Vol. 50 No. 4, pp.6-30.

Buffardi, L.E. and Campbell, W.K. (2008), "Narcissism and social networking web sites", Personality and Social Psychology Bulletin, Vol. 34 No. 10, pp.1303-1314.

Chauhan, K. and Pillai, A. (2013), "Role of content strategy in social media brand communities: a case of higher education institutes in India", Journal of Product \& Brand Management, Vol. 22 No. 1, pp. 40-51.

Chen, G.M. (2011), "Tweet this: A uses and gratifications perspective on how active Twitter use gratifies a need to connect with others", Computers in Human Behavior, Vol. 27 No. 2, pp. 755-762.

Cheung, C.M., Chiu, P.Y. and Lee, M.K. (2011), "Online social networks: Why do students use Facebook?", Computers in Human Behavior, Vol. 27 No. 4, pp.1337-1343.

Chi, H. (2011), "Interactive digital advertising vs. virtual brand community", Journal of Interactive Advertising, Vol. 12 No. 1, pp. 44-61.

Cvijikj, I.P. and Michahelles, F. (2013), "Online engagement factors on Facebook brand pages”, Social Network Analysis and Mining, Vol. 3 No. 4, pp. 843-861.

De Vries, L., Gensler, S. and Leeflang, P.S. (2012), "Popularity of brand posts on brand fan pages: An investigation of the effects of social media marketing", Journal of Interactive Marketing, Vol. 26 No. 2, pp.83-91.

De Vries, L., Peluso, A.M., Romani, S., Leeflang, P.S. and Marcati, A. (2017), "Explaining consumer brand-related activities on social media: An investigation of the different roles of self-expression and socializing motivations", Computers in Human Behavior, Vol. 75, pp. 272282.

Ellison, N.B., Steinfield, C. and Lampe, C. (2007), "The benefits of Facebook "friends": Social capital and college students' use of online social network sites", Journal of Computer-mediated Communication, Vol. 12 No. 4, pp.1143-1168.

Fornell, C. and Larcker, D.F. (1981), "Structural equation models with unobservable variables and measurement error", Algebra and Statistics, Vol. 18 No. 3, pp. 382-388.

Fu, P.W., Wu, C.C. and Cho, Y.J. (2017), "What makes users share content on Facebook? Compatibility among psychological incentive, social capital focus, and content type", Computers in Human Behavior, Vol. 67, pp.23-32.

Hair, J.F., Black W.C., Babin, B.J. and Anderson, R.E. (2010), Multivariate Data Analysis, Prentice Hall, New Jersey.

Jahn, B. and Kunz, W. (2012), "How to transform consumers into fans of your brand", Journal of Service Management, Vol. 23 No. 3, pp. 344-361.

Joinson, A.N. (2008), "Looking at, looking up or keeping up with people? Motives and use of Facebook', In Proceedings of the SIGCHI conference on Human Factors in Computing Systems, pp. 1027-1036.

Kaplan, A. M. and Haenlein, M. (2010), "Users of the world, unite! The challenges and opportunities of social media", Business Horizons, Vol. 53 No. 1, pp. 59-68.

Karpinska-Krakowiak, M. and Modlinski, A. (2020), "Popularity of branded content in social media”, Journal of Computer Information Systems, Vol. 60 No. 4, pp. 309-315.

Katz, E. (1959), "Mass communications research and the study of popular culture: An editorial note on a possible future for this journal", Studies in Public Communication, Vol. 22, pp. 1-6. Leckie, C., Nyadzayo, M. W., \& Johnson, L. W. (2016), "Antecedents of consumer brand engagement and brand loyalty", Journal of Marketing Management, Vol. 32 No. 5-6, pp. 558578 . 
Lee, E., Ahn, J. and Kim, Y.J. (2014), "Personality traits and self-presentation at Facebook", Personality and Individual Differences, Vol. 69, pp.162-167.

Luarn, Pin, Yu-Fan Lin, and Yu-Ping Chiu (2015), "Influence of Facebook brand-page posts on online engagement", Online Information Review, Vol. 39 No. 4, 2015, pp. 1-16.

Malthouse, E.C. and Calder, B.J. (2010), "Media placement versus advertising execution", Advances in Advertising Research, Vol. 1, pp. 333-345.

McQuail, D. (1983), Mass Communication Theory, Sage Publications, London.

Moran, G., Muzellec, L. and Johnson, D. (2019), "Message content features and social media engagement: evidence from the media industry", Journal of Product \& Brand Management, ahead-of print. https://doi.org/10.1108/JPBM-09-2018-2014

Muntinga, D.G., Moorman, M. and Smit, E.G. (2011), "Introducing COBRAs: Exploring motivations for brand-related social media use", International Journal of Advertising, Vol. 30 No. 1, pp.13-46.

Ong, E.Y., Ang, R.P., Ho, J.C., Lim, J.C., Goh, D.H., Lee, C.S. and Chua, A.Y. (2011), "Narcissism, extraversion and adolescents' self-presentation on Facebook", Personality and Individual Differences, Vol. 50 No. 2, pp.180-185.

Park, N., Kee, K. F. and Valenzuela, S. (2009), "Being immersed in social networking environment: Facebook groups, uses and gratifications, and social outcomes", CyberPsychology \& Behavior, Vol. 12 No. 6, pp. 729-733.

Phua, J., Jin, S.V. and Kim, J.J. (2017), "Gratifications of using Facebook, Twitter, Instagram, or Snapchat to follow brands: The moderating effect of social comparison, trust, tie strength, and network homophily on brand identification, brand engagement, brand commitment, and membership intention", Telematics and Informatics, Vol. 34 No. 1, pp. 412-424.

Quan-Haase, A. and Young, A.L. (2010), "Uses and gratifications of social media: A comparison of Facebook and instant messaging", Bulletin of Science, Technology \& Society, Vol. 30 No. 5, pp.350-361.

Raacke, J. and Bonds-Raacke, J.B. (2008), "MySpace and Facebook: applying the uses and gratifications theory to exploring friend-networking sites", CyberPsychology \& Behavior, Vol. 11,pp. 169-74.

Ryan, R.M. and Deci, E.L. (2000), "Intrinsic and extrinsic motivations: Classic definitions and new directions", Contemporary Educational Psychology, Vol. 25 No. 1, pp.54-67.

Schivinski, B., Christodoulides, G. and Dabrowski, D. (2016), "Measuring consumers' engagement with brand-related social-media content: Development and validation of a scale that identifies levels of social-media engagement with brands", Journal of Advertising Research, Vol. 56 No. 1, pp.64-80.

Shao, G. (2009), "Understanding the appeal of user-generated media: a uses and gratification perspective", Internet Research, Vol. 19 No. 1, pp. 7-25.

Schau, H. and Gilly, M. (2003), "We are what we post? Selfpresentation in personal web space", Journal of Consumer Research, Vol. 30, pp. 385-404.

Sheldon, K. M., Abad, N. and Hinsch, C. (2011), "A two-process view of Facebook use and relatedness need-satisfaction: Disconnection drives use, and connection rewards it", Journal of Personality and Social Psychology, Vol. 100 No. 4, pp. 766-775.

Tennie, C., Frith, U. and Frith, C.D. (2010), "Reputation management in the age of the worldwide web", Trends in Cognitive Sciences, Vol. 14 No. 11, pp.482-488.

Thongmak, M. (2015), "Engaging Facebook users in brand pages: Different posts of marketing-mix information", In International Conference on Business Information Systems, Springer, Cham, pp. 299-308.

Toubia, O. and Stephen, A.T. (2013), "Intrinsic vs. image-related utility in social media: Why do people contribute content to Twitter?”, Marketing Science, Vol. 32 No. 3, pp.368-392. 
Trepte, S. (2005), "Daily talk as self-realization: An empirical study on participation in daily talk shows", Media Psychology, Vol. 7 No. 2, pp.165-189.

Tsai, W.H.S. and Men, L.R. (2013), "Motivations and antecedents of consumer engagement with brand pages on social networking sites", Journal of Interactive Advertising, Vol. 13 No. 2, pp.76-87.

Tsimonis, G. and Dimitriadis, S. (2014), "Brand strategies in social media", Marketing Intelligence \& Planning, Vol. 32 No. 3, pp. 328-344

Underwood, J. D., Kerlin, L., and Farrington-Flint, L. (2011), "The lies we tell and what they say about us: using behavioural characteristics to explain Facebook activity", Computers in Human Behavior, Vol. 27 No. 5, pp. 1621-1626.

Van Doorn, J., Lemon, K.N., Mittal, V., Nass, S., Pick, D., Pirner, P. and Verhoef, P.C. (2010), "Customer engagement behavior: Theoretical foundations and research directions", Journal of Service Research, Vol. 13 No. 3, pp.253-266.

Vargo, C.J. (2016), "Toward a tweet typology: Contributory consumer engagement with brand messages by content type", Journal of Interactive Advertising, Vol. 16 No. 2, pp.157-168.

Walsh, G., Gwinner, K.P. and Swanson, S.R. (2004), "What makes mavens tick? Exploring the motives of market mavens' initiation of information diffusion", Journal of Consumer Marketing, Vol. 21 No. 2, pp. 109-122.

Zhao, S., Grasmuck, S. and Martin, J. (2008), "Identity construction on Facebook: Digital empowerment in anchored relationships", Computers in Human Behavior, Vol. 24 No. 5, pp.1816-1836. 